\title{
Gene transfer in Nicotiana rustica by means of irradiated pollen V. Quantitative characters
}

\author{
M. A. Cornish and \\ C. P. Werner
}

Department of Genetics, University of Birmingham, Birmingham B15 2TT, U.K.

The inheritance of two quantitative characters is examined in the $\mathbf{M}_{2}$ and backcross generations derived from crosses of Nicotiana rustica that used pollen irradiated with $20 \mathrm{Krad}$ of $\boldsymbol{\gamma}$-rays. All generations examined show, on average, a reduction in final height compared with their unirradiated controls. Leaf width was also reduced in almost all cases. Whilst in some parental combinations the direction of this change is compatible with the concept of restricted transfer of genes from the original pollen parent in other cases it is not. Instead the consistent trend across all generations is better explained as a consequence of the expression of deleterious mutations that lead to a general reduction in vigour. Differences between the two backcross generations provide some evidence of selection in the $\mathbf{M}_{1}$ pollen against radiation damage, acting in general to improve vigour. It is concluded that the maternal trends previously reported in this species were entirely the result of induced mutations, reducing the expression of the characters concerned. No evidence can be found from this species for the existence of a mechanism for gene transfer by DNA fragment incorporation.

\section{INTRODUCTION}

The initial paper in this series (Caligari et al., 1981) described the effects of pollen irradiation in Nicotiana rustica and showed that the second $\left(\mathrm{M}_{2}\right)$ generatión after irradiation appeared more maternal than the $\mathrm{F}_{2}$ both for qualitatively and quantitatively inherited characters. Although three mechanisms were proposed by these authors to explain their findings the favoured mechanism was the restricted transfer of the paternal genome, perhaps similar to one of the mechanisms proposed by Pandey $(1975 ; 1980)$. The potential of this approach as a rapid plant breeding method generated enthusiasm (Davies, 1981; Mather, 1981). Subsequent work with the same inbred lines of $N$. rustica, however, has shown the consequences of pollen irradiation in this species to be less promising than originally hoped (Werner et al., 1984; Werner and Cornish, 1984; 1985). Cytogenetical studies have revealed that the $M_{1}$ generation possesses numerous chromosomal aberrations and that these are inherited by subsequent generations. The radiation has also been shown to induce the loss of function of alleles controlling pigment synthesis in this species. Mutations of these kinds have regularly been reported following radiation treat- ment and have little value in plant breeding. Snape et al. (1983) have, however, proposed that the maternal trends observed may result from selection in the $\mathbf{M}_{1}$ gametophytes or the $\mathbf{M}_{2}$ zygote against radiation damaged paternal chromosomes and that this may provide a valuable mechanism for restricted gene transfer during a plant breeding programme. Selection at this stage has indeed been observed in the $N$. rustica study, resulting in the reduced frequency of transmission of structurally aberrant chromosomes to the second generation and in disturbances of the segregations of major genes. The intensity of selection was, however, considered to be too low to be of practical value. In this, the final paper in the series, we report the effects of pollen irradiation in this material on the inheritance of quantitative characters, which being under the control of a number of genes indicate the effects of radiation across the whole genome.

\section{MATERIALS AND METHODS}

Nine quantitative characters were assessed on the same field experiment from which the qualitative results were obtained. The design and composition of this experiment were described fully in our 
previous paper (Werner and Cornish, 1985). $\mathbf{M}_{1}$ plants were produced from the pollination of $V_{27}$ plants with irradiated $V_{27}$ pollen at $20 \mathrm{Krad}$ (treatment $20 \mathrm{~A}$ ) and with irradiated $\mathrm{V}_{12}$ pollen (20B) and of $V_{12}$ plants with irradiated $V_{27}$ pollen (20C) and irradiated $V_{12}$ pollen $(20 \mathrm{D})$. The $\mathrm{M}_{1}$ plants were then selfed $\left(M_{2}\right)$ and reciprocally backcrossed $\left(V_{27} \times M_{1}=B C, M_{1} \times V_{27}=R B C\right)$. The results of two quantitative characters will be reported in detail here. These are leaf width, the maximum width of the largest leaf measured 6 weeks after planting, and final height, the height reached at the end of the growing season. Leaf width was chosen for detailed presentation because owing to its genetic architecture it offers the most discriminating test of the restricted gene transfer hypothesis. Final height is a maturity character, generally considered to give consistent results over seasons in this species and was also presented in the initial study by Caligari et al. (1981). The results of the remaining characters are summarised here but are described in detail by Werner (1984).

\section{RESULTS}

At final height $\mathrm{V}_{12}$ was taller than $\mathrm{V}_{27}$ and both the $F_{1}$ and $F_{2}$ were on average taller than $V_{12}$ (Table
1). The same relationships were found by Caligari et al. (1981) for this character although all their generations were on average taller than ours as a result of a seasonal difference. The $20 \mathrm{~B} \mathrm{M}_{2}$ generation is equivalent to the $20 \mathrm{Krad}(\mathrm{G})$ treatment of Caligari et al. and the two generations show the same relationship to their basic generations, being significantly shorter than their respective $F_{2}$ 's. The additional generations included in this study provide a similar picture; the mean of the $M_{2}$ from the reciprocal cross, $20 \mathrm{C}$, is also shorter than the $\mathrm{F}_{2}$; the two irradiated self $\mathrm{M}_{2}$ 's are shorter than their respective parents although only the 20D $\mathrm{M}_{2}$ is significantly shorter; seven of the eight backcross generations are shorter than their unirradiated equivalent, five of the differences being significant.

Now if restricted gene transfer were the cause of these trends the 20B $\mathrm{M}_{2}$ would have inherited more maternal genome than paternal and would, therefore, be more like $\mathrm{V}_{27}$, that is shorter than the $\mathrm{F}_{2}$. This is indeed the case as Caligari et al. (1981) also observed. For the same reason we would also expect the $20 \mathrm{C} \mathrm{M}_{2}$ to be more like $V_{12}$, that is a little shorter than the $F_{2}$. It is however reduced in height beyond $V_{12}$ and is therefore shorter than would be expected on the basis of the gene transfer hypothesis. We would expect the two backcrosses derived from the $20 \mathrm{~B} \mathrm{M}_{1}$ 's to be shorter than $\mathrm{B}$

Table 1 Generation means and comparisons with their control generations for two quantitative characters. The standard errors and their degrees of freedom are derived from the between families mean squares when significant, and from the within families mean square otherwise. The approximation of Satterthwaite has been used to obtain the appropriate degrees of freedom of $t^{\prime}$ (Snedecor and Cochran, 1980). Inequalities indicated are significant at the 5 per cent level

\begin{tabular}{|c|c|c|c|c|c|c|c|c|c|}
\hline \multirow{2}{*}{\multicolumn{2}{|c|}{ Generation }} & \multirow[b]{2}{*}{ mean } & \multicolumn{3}{|c|}{ Final Height $(\mathrm{cm})$} & \multicolumn{4}{|c|}{ Leaf Width $(\mathrm{mm})$} \\
\hline & & & \multirow{2}{*}{$\begin{array}{l}\text { s.e. } \\
1 \cdot 01\end{array}$} & \multirow{2}{*}{$\begin{array}{r}\text { d.f. } \\
59\end{array}$} & $t^{\prime}$ test & mean & \multirow{2}{*}{$\frac{\text { s.e. }}{4.53}$} & \multirow{2}{*}{$\begin{array}{r}\text { d.f. } \\
59\end{array}$} & $t^{\prime}$ test \\
\hline & $\mathrm{V}_{27}$ & 98.93 & & & & $252 \cdot 0$ & & & \\
\hline & $\mathrm{V}_{12}$ & $137 \cdot 52$ & $1 \cdot 60$ & 59 & & $201 \cdot 3$ & $4 \cdot 38$ & 59 & \\
\hline & $F_{1}$ & $171 \cdot 40$ & $1 \cdot 78$ & 58 & & $252 \cdot 9$ & $5 \cdot 98$ & 3 & \\
\hline & $\mathrm{F}_{2}$ & $152 \cdot 72$ & $2 \cdot 00$ & 159 & & $230 \cdot 2$ & $4 \cdot 10$ & 158 & \\
\hline & $B\left(F_{1} \times V_{27}\right)$ & $142 \cdot 53$ & 3.99 & 7 & & $247 \cdot 2$ & $3 \cdot 42$ & 156 & \\
\hline $20 \mathrm{~A}$ & $\mathbf{M}_{2}$ & $90 \cdot 39$ & $7 \cdot 25$ & 3 & $=\mathrm{V}_{27}$ & $207 \cdot 4$ & $13 \cdot 48$ & 3 & $=\mathrm{V}_{27}$ \\
\hline $20 \mathrm{~B}$ & $\mathbf{M}_{2}$ & $123 \cdot 96$ & $2 \cdot 05$ & 223 & $<\mathrm{F}_{2}$ & $183 \cdot 8$ & $5 \cdot 51$ & 11 & $<\mathrm{F}_{2}$ \\
\hline $20 \mathrm{C}$ & $\mathbf{M}_{2}^{2}$ & $126 \cdot 29$ & $4 \cdot 33$ & 18 & $<\mathrm{F}_{2}$ & $182 \cdot 1$ & $8 \cdot 26$ & 18 & $<\mathrm{F}_{2}$ \\
\hline $20 \mathrm{D}$ & $\mathbf{M}_{2}$ & $127 \cdot 34$ & $2 \cdot 80$ & 6 & $<\mathrm{V}_{12}$ & $167 \cdot 7$ & 8.96 & 6 & $<\mathrm{V}_{12}$ \\
\hline \multirow{2}{*}{$20 \mathrm{~A}$} & $\mathrm{BC}$ & $100 \cdot 47$ & $2 \cdot 53$ & 5 & $=\mathrm{V}_{27}$ & $253 \cdot 0$ & $5 \cdot 89$ & 48 & $=V_{27}$ \\
\hline & $\mathrm{RBC}$ & $96 \cdot 29$ & $2 \cdot 35$ & 37 & $\begin{aligned} & =\mathrm{V}_{27} \\
\mathrm{RBC} & =\mathrm{BC}\end{aligned}$ & $227 \cdot 8$ & $5 \cdot 47$ & 37 & $\begin{aligned} & <\mathrm{V}_{27} \\
\mathrm{RBC} & <\mathrm{BC}\end{aligned}$ \\
\hline \multirow{2}{*}{$20 \mathrm{~B}$} & $\mathrm{BC}$ & $131 \cdot 75$ & $2 \cdot 23$ & 23 & $<\mathrm{B}$ & $228 \cdot 8$ & $3 \cdot 45$ & 23 & $<\mathrm{B}$ \\
\hline & $\mathrm{RBC}$ & $124 \cdot 24$ & $2 \cdot 33$ & 23 & $\begin{aligned} & <\mathrm{B} \\
\mathrm{RBC} & <\mathrm{BC}\end{aligned}$ & $214 \cdot 3$ & $3 \cdot 16$ & 23 & $\begin{aligned} & <\mathrm{B} \\
\mathrm{RBC} & <\mathrm{BC}\end{aligned}$ \\
\hline \multirow{2}{*}{$20 \mathrm{C}$} & $\mathrm{BC}$ & $137 \cdot 98$ & $2 \cdot 19$ & 169 & $=\mathrm{B}$ & $234 \cdot 7$ & 3.47 & 171 & $<\mathrm{B}$ \\
\hline & $\mathrm{RBC}$ & $128 \cdot 88$ & $2 \cdot 89$ & 15 & $\begin{aligned}< & <\mathrm{B} \\
\mathrm{RBC} & <\mathrm{BC}\end{aligned}$ & $219 \cdot 9$ & $4 \cdot 92$ & 15 & $\begin{aligned} & <\mathrm{B} \\
\mathrm{RBC} & <\mathrm{BC}\end{aligned}$ \\
\hline \multirow[t]{2}{*}{$20 \mathrm{D}$} & $\mathrm{BC}$ & $161 \cdot 62$ & $1 \cdot 83$ & 26 & $<\mathrm{F}_{1}$ & $238 \cdot 0$ & $3 \cdot 80$ & 27 & $=F_{1}$ \\
\hline & $\mathrm{RBC}$ & $160 \cdot 20$ & $2 \cdot 39$ & 13 & $\begin{aligned} &<\mathrm{F}_{1} \\
& \mathrm{RBC}=\mathrm{BC}\end{aligned}$ & $234 \cdot 8$ & $4 \cdot 71$ & 26 & $\begin{aligned}< & <\mathrm{F}_{1} \\
\mathrm{RBC} & =\mathrm{BC}\end{aligned}$ \\
\hline
\end{tabular}


and more like $\mathrm{V}_{27}$, which they are. The two $20 \mathrm{C}$ backcrosses on the other hand should be more like the $F_{1}$ than B, i.e. taller, which they are not. Finally, we would expect none of the generations derived from the irradiated selfs to differ from their unirradiated equivalents but all three $20 \mathrm{D}$ generations are significantly shorter. In some generations the reduction in height can be explained in terms of the restricted transfer of the paternal genome into a maternal background. The combined results of all the generations presented here, however, are not consistent with this explanation. Instead it is clear that there is a reduction in height of all the generations regardless of the directions of the cross. Such a trend would result from the inheritance of induced deleterious mutations leading to a loss of vigour and hence to a reduction in height in all cases.

The leaf width character provides an even clearer illustration of this effect. The relationship between the parents is now reversed since $V_{27}$ has wider leaves than $V_{12}$ whilst the $F_{2}$ is intermediate. Again in almost all generations the radiation has significantly reduced leaf width as compared with the control generations. Instead of the maternal trend towards wider leaves in the $20 \mathrm{~B} \mathrm{M}_{2}$ that would result from restricted gene transfer we observed considerably narrower leaves than the $\mathrm{F}_{2}$. The $20 \mathrm{~B}$ and $20 \mathrm{C}$ backcrosses also have thinner leaves contrary to gene transfer expectations and the $20 \mathrm{D} \mathrm{M}_{2}$ progeny have on average the thinnest leaves of any generation. Whilst leaf width was not described by Caligari et al. (1981), because in their experiment the parents were not significantly different from each other, it was measured
(Ingram, 1982) and a marked, dose-related reduction in width was observed similar to the trend described here. The expression of deleterious induced mutations would appear, therefore, to be the overriding phenotypic consequence of the irradiation on this character also.

Similar results were obtained for the remaining seven quantitative characters measured on these plants (table 2). Six of these, including earlier height measurements and leaf and flower dimensions, showed a consistent reduction in expression independently of the direction of the cross although not all the reductions were significant at the 5 per cent level. The remaining character, which showed consistent trends towards increased expression, was flowering time, but an increase in the time taken for a plant to flower can also be interpreted as a reduction in vigour as a result of deleterious mutations. The radiation treatment also affected the variation within many of the $\mathrm{M}_{2}$ and backcross families. Taken over all nine characters more than one third of the generations had average within family variances significantly greater than within their equivalent unirradiated generations. Similar effects were found by Ingram (1982). Induced mutations should indeed inflate the variation within families. The restricted transfer of the paternal genome on the other hand would be expected to lead to a reduction in this variation since fewer loci would be segregating in the second generation.

Further information about the effects of the radiation can be obtained from a comparison of the $B C$ and $R B C$ generations. The genetical expectations of these two generations are identical

Table 2 Significant relationships ( 5 per cent level) between treatment means and control means; from Students $t^{\prime}$ tests. The characters are: FT, flowering time; FL, flower length; FW, flower width; LL, leaf length; LW, leaf width; RUF, ruffled leaf index; HFT, height at flowering time; H50, height at 50 per cent flowering; $\mathrm{FH}$, final height

\begin{tabular}{lllllllllll}
\hline Generation & FT & FL & FW & LL & LW & RUF & HFT & H50 & FH & $\begin{array}{l}\text { Control } \\
\text { generation }\end{array}$ \\
\hline $20 \mathrm{~A} \mathrm{M}_{2}$ & $=$ & $<$ & $=$ & $<$ & $=$ & $=$ & $=$ & $=$ & $=$ & $\mathrm{V}_{27}$ \\
$20 \mathrm{~B} \mathrm{M}_{2}$ & $=$ & $=$ & $=$ & $<$ & $<$ & $=$ & $<$ & $<$ & $<$ & $F_{2}$ \\
$20 \mathrm{C} \mathrm{M}_{2}$ & $>$ & $=$ & $<$ & $<$ & $<$ & $=$ & $<$ & $<$ & $<$ & $\mathrm{F}_{2}$ \\
$20 \mathrm{D} \mathrm{M}_{2}$ & $=$ & $=$ & $<$ & $<$ & $<$ & $=$ & $=$ & $=$ & $<$ & $\mathrm{V}_{27}$ \\
$20 \mathrm{~A} \mathrm{BC}$ & $=$ & $=$ & $=$ & $=$ & $=$ & $=$ & $=$ & $=$ & $=$ & $\mathrm{V}_{27}$ \\
$20 \mathrm{~A} \mathrm{RBC}$ & $=$ & $=$ & $=$ & $<$ & $<$ & $=$ & $=$ & $=$ & $=$ & $\mathrm{V}_{27}$ \\
$20 \mathrm{~B} \mathrm{BC}$ & $=$ & $=$ & $=$ & $<$ & $<$ & $=$ & $=$ & $<$ & $<$ & $\mathrm{B}$ \\
$20 \mathrm{~B} \mathrm{RBC}$ & $>$ & $=$ & $=$ & $<$ & $<$ & $=$ & $=$ & $<$ & $<$ & $\mathrm{B}$ \\
$20 \mathrm{C}$ BC & $=$ & $=$ & $=$ & $=$ & $<$ & $<$ & $=$ & $=$ & $=$ & $\mathrm{B}$ \\
$20 \mathrm{C}$ RBC & $>$ & $<$ & $<$ & $<$ & $<$ & $<$ & $=$ & $<$ & $<$ & $\mathrm{B}$ \\
$20 \mathrm{D} \mathrm{BC}$ & $=$ & $=$ & $=$ & $=$ & $=$ & $=$ & $=$ & $=$ & $<$ & $\mathrm{F}_{1}$ \\
$20 \mathrm{D} \mathrm{RBC}$ & $=$ & $=$ & $=$ & $=$ & $<$ & $=$ & $=$ & $<$ & $<$ & $\mathrm{F}_{1}$ \\
\hline
\end{tabular}


unless there are maternal effects or unless the rates of transmission of damaged chromosomes differ in the male and female gametophytes. It can be seen in table 1 that the scores of the RBC generations are in all eight cases lower than their $\mathrm{BC}$ generations, six of the differences being significant. It is possible that the reduced vigour of these RBC generations is a maternal effect since the seed parents in these crosses were $M_{1}$ plants and may not have produced as healthy seed as normal $V_{27}$ plants. However, reduced seed quality would be expected to have a greater effect on characters measured earlier in the growing season than final height but this was not the case. A more likely explanation is that selection was acting, in the $M_{1}$ pollen that produced the $B C$ generations, against damaged chromosomes of paternal origin, whilst less selection or no selection was acting in the ovules that produced the RBC generations. Since damaged chromosomes on the whole lead to a loss of vigour the $B C$ generations, having inherited less damaged material, are more vigorous both for final height and leaf width. Note that the direction of this effect on quantitative characters is independent of the direction of the cross; selection does not produce a more maternal phenotype but a more normal phenotype. Only selection against mutations at loci for which the parents originally differed would be expected to produce a maternal bias. Selection against mutations at loci for which the parents are identical on the other hand would restore normal expression. It would appear that the latter kind of mutation predominates in these two characters and in most of the other characters that showed significant differences. Selection would also be expected to reduce the within family variances of the $\mathrm{BC}$ generations relative to their $\mathrm{RBC}$ generations; in 10 of the 36 comparisons over the nine characters significant differences were observed and in all 10 cases the $\mathrm{BC}$ generations had smaller variances.

In addition to the generation means the means of the families within each generation were also compared with the control generations to determine whether any individual families behaved abnormally as a result of a rare gene transfer event. Some families for some characters departed significantly from the control generations in the opposite direction to their generation means. A few families flowered earlier than their control, for example, whilst others had significantly larger flowers. Almost all deviations in the three height characters on the other hand were towards reduced expression. The pattern of departures bore no relationship to the directions of the original crosses but were scattered through all generations so that many of the deviant families departed in the opposite direction from that expected as a result of gene transfer. They do not, therefore, provide any evidence of the operation of a rare and unusual genetic mechanism. Instead these anomalous deviations would appear related to the genetic architectures of the characters concerned as Lawrence (1975) found in Arabidopsis thaliana. Flowering time for example exhibits ambidirectional dominance in N. rustica (Mather and Jinks, 1982). This is consistent with a history of stabilising selection for this character which would lead to the fixation both of functionally active increasing alleles and functionally active decreasing alleles. The mutation of these two kinds of loci to a functionless form would then affect the character in opposite directions. Final height on the other hand has probably been subjected in the past to directional selection for increasing expression resulting in directional dominance. Few functionally active decreasing alleles will have been fixed so that very few mutations to a functionless form will increase final height.

The results described are from the treatment of pollen with $20 \mathrm{Krad}$ of gamma rays. The field experiment also included a full set of 12 generations derived from a $10 \mathrm{Krad}$ treatment and the four $\mathrm{M}_{2}$ generations from a $2 \mathrm{Krad}$ treatment. The lower doses produced effects very similar in direction to those from $20 \mathrm{Krad}$, but reduced in magnitude (Werner, 1984).

\section{DISCUSSION}

The effects of pollen irradiation on the quantitatively inherited characters described here are entirely consistent with the effects observed in the preliminary study of this material (Caligari et al., 1981; Ingram, 1982). In some instances the radiation induced a change in mean expression of a quantitative character that led to a greater similarity to the maternal parent. The additional generations described in this study show that this maternal trend is found only in certain parental combinations. Instead the consistent effect of the radiation has been, as a consequence of the expression of deleterious mutations, to reduce plant vigour with a concomitant reduction in all characters for which decreasing expression indicates decreasing vigour. Seed irradiation is known to have similar effects in this species (Ingram and Jinks, 1982; Ingram, 1982). This conclusion is in line with the 
conclusions of the other studies in this series which provided evidence of induced chromosomal damage and of major gene mutations in this material.

Note that the magnitude of the reduction in vigour is not equal for all generations. For example, the $20 \mathrm{~B}$ and $20 \mathrm{C} \mathrm{M}_{2}$ generations show a greater reduction in final height (as compared with the equivalent unirradiated generation) than do the 20A and 20D $\mathrm{M}_{2}$ 's. A similar effect was observed by Powell and Caligari (1985) who were unable to find any significant reduction in vigour in $\mathbf{M}_{2}$ generations of barley derived by selfing even though $\mathbf{M}_{2}$ generations derived from the same parents by crossing had shown such a reduction (Powell et al., loc. cit.). This effect is a consequence of the generally recessive nature of induced mutations and is consistent with conventional mutational effects as the following simple model illustrates. Consider a quantitative character controlled by a number of segregating loci for each of which the increasing allele is completely dominant to the decreasing allele and where both alleles mutate to a recessive mutant indistinguishable from the decreasing allele. (This model describes perfectly the effect of irradiation on the major gene controlling ovary colour in this material (Werner and Cornish, 1985).) Irradiation of the decreasing allele will have no effect on phenotype. Selfing with irradiated pollen will produce $\mathbf{M}_{1}$ plants heterozygous for the mutant allele and the dominant increasing allele. Each recessive allele will therefore influence the phenotypes of only the one in four $\mathrm{M}_{2}$ individuals that are homozygous for the mutant allele. Crossing with irradiated pollen, on the other hand, will produce a more marked effect since when mutation occurs the $\mathbf{M}_{2}$ generation, being derived from $M_{1}$ plants heterozygous for the decreasing allele and the mutant allele, will permit expression of the mutant allele both in the individuals homozygous for it and in the individuals heterozygous for it and the decreasing allele. On crossing, therefore, the mutant allele will influence the phenotype of three-quarters of the $M_{2}$ generation. If both parents possess some increasing alleles then the $\mathbf{M}_{2}$ generations from both the irradiated selfs will show some decline in expression, but the equivalent irradiated crosses will show a rather greater decline. Whilst there is no reason to believe that all loci affecting a quantitative character behave on irradiation in such a simple manner the model serves to illustrate that the observed differences in response between the $\mathbf{M}_{2}$ generations are not inconsistent with conventional mutational effects.
The consistent reciprocal differences in the backcross generations can be interpreted as evidence of selection in the male gametophyte against radiation damage. This again is in agreement with our previous findings. The proposal of Snape et al. (loc. cit.) that selection of this kind would lead to useful maternal trends is not however supported by these results which show that selection acts in all cases to restore some of the vigour lost as a result of the radiation damage. The irradiation of $N$. rustica pollen therefore provides no evidence for the existence of a genetic mechanism that might be used for the rapid transfer of paternal genes. Whilst disturbed segregations of major genes were observed in favour of the maternal alleles such effects were slight and, in this species at least, achieved only at the expense of considerable deleterious radiation damage.

Finally, it is worthwhile to compare our findings with studies of pollen irradiation in other species. The $N$. rustica results, in common with all other reported studies, fail to provide any additional evidence to support the unusual mechanisms for gene transfer proposed by Pandey $(1975 ; 1980$; 1983). For example, Sanford et al. (1984a, b) and Chyi et al. (1984) examined a total of 87,000 potential transformation events in a range of crop species but failed to find any transformants. Furthermore, in an unpublished study of our own, attempts to transfer the dominant allele for red flower colour from $N$. forgetiana to $N$. alata, two species used by Pandey, also failed. 26 pollinations using a mixture of self-incompatible $N$. alata pollen and $N$. forgetiana pollen irradiated with $100 \mathrm{Krad}$ of gamma-rays produced 251 offspring. 238 of these plants flowered but all had white flowers and appeared to be self progeny of $N$. alata. Pandey's own results, therefore, provide the only evidence that supports his theories.

The cytogenetical effects that have been described earlier in this series are entirely consistent with other published consequences of pollen irradiation including the more recent studies of Snape et al. and Powell et al. (1983). With the exception of some of the results of Powell et al. the behaviour of the major genes described in our previous paper is also in agreement with the results of a number of other workers. Fewer studies of the effects of pollen irradiation on quantitative characters have been made. The three quantitative characters examined by Snape et al. in Triticum aestivum show a decline in expression following irradiation in a manner similar to that reported here; for ear length this is in the maternal direction; for grain number the decline is beyond that of the 
maternal parent suggesting considerable loss of fertility in the $\mathbf{M}_{2}$ generation; for plant height this trend is in the paternal direction and is explained by the authors as "a carry-over effect of the radiation damage". Similarly four of the five characters described by Powell et al. and Caligari et al. (1984) on Hordeum vulgare also show a decline following irradiation but in these cases, as in the original $N$. rustica cross, the maternal parent is less vigorous. A true maternal trend again cannot be distinguished from mutational loss in this limited study. The fifth character, grain number, shows a decline at the lowest radiation dose used, increasing to normality at the highest dose, an unexpected trend. Both these studies are largely in agreement with ours in suggesting that mutational loss is the major cause of the phenotypic deviations observed. The Hordeum work, however, offers some evidence that may be interpreted as indicating the operation of a strong selection mechanism against radiation damage although others working with this species did not find this (Donini et al., 1970; Devreux et al., 1972). Firm conclusions must await a more exhaustive examination of this species.

Acknowledgements Financial support from the Agricultural and Food Research Council and a research studentship from the Science and Engineering Research Council to C.P.W. are gratefully acknowledged. We would like to thank Professor J. L. Jinks and Dr G. H. Jones for their valuable advice and encouragement throughout the duration of this project.

\section{REFERENCES}

CALIGARI, P. D. S., INGRAM, N. R. AND JINKS, J. L. 1981. Gene transfer in Nicotiana rustica by means of irradiated pollen. I. Unselected progenies. Heredity, 47, 17-26.

CALIGARI, P. D. S., POWELl, W. AND HAYTER, A. M. 1984. Quantitatively varying characters in the second generation from an irradiated pollen cross in barley. Heredity, 52, 347-353.

CHYI, Y. S., SANFORD, J. C. AND REISCH, B. I. 1984. Further attempts to induce egg-transformation using irradiated pollen. Theoretical and Applied Genetics, 68, 277-283.

DAVIES, D. R. 1981. Gene transfer in plants. Nature, 291, 531532.

DEVREUX, M., DONINI, B. AND SCARASCIA-MUGNOZZA, G. T. 1972. Genetic effects of gametophyte irradiation in barley. II. Frequency and types of mutations induced. Radiation Botany, 12, 87-98.
DONINI, B., DEVREUX, M. AND SC.ARASCIA-MUGNOZZA, G. T. 1970. Genetic effects of gametophyte irradiation in barley. I. Seedling mutants. Radiation Botany, 10, 79-86.

INGRAM, N. R. 1982. Uses of ionizing radiation in plant breeding. Ph.D. Thesis, University of Birmingham.

INGRAM, N. R. AND JINKS, J. L. 1982. Analysis of induced quantitative variation. II. The recombinant inbred lines. Heredity, 48; $; 79-83$.

LAWRENCE, C. W. 1975. Radiation induced polygenic mutation in Arabidopsis thaliana. III. Effect of parental genotype and the limits of change. Heredity, 34, 189-201.

MAther, K. 1981. Perspective and prospect. Philosophical Transactions of the Royal Society, London, B, 292, 601-609.

MATHLR, K. AND JINKS, J. L. 1982. Biometrical Genetics. 3rd edition. Chapman and Hall, London.

PANDEY, K. K. 1975. Transformation, incompatibility and plant improvement. Incompatibility Newsletter, 6, 91-121.

PANDEY, K. K. 1980. Further evidence for egg transformation in Nicotiana. Heredity, 45, 17-31.

PANDEY, K. K. 1983. Evidence for genetic transfer by the use of sublethally irradiated pollen in Zea mays and theory of occurrence by chromosome repair through somatic recombination and gene conversion. Molecular and General Genetics, 191, 358-365.

POWELL, W. AND CALIGARI, P. D. S. 1985. Irradiated pollen selfs in cultivars of Hordeum vulgare. Heredity, 54.

POWELl, W., CALIGARI, P. D. S. AND HAYTER, A. M. 1983. The use of pollen irradiation in barley breeding. Theoretical and Applied Genetics, 65, 73-76.

SANFORD, J. C., CHYI, Y. S. AND REISCH, B. I. 1984a. An attempt to induce egg transformation in Lycopersicon esculentum Mill. using irradiated pollen. Theoretical and Applied Genetics, 67, 553-558.

SANFORD, J. C., CHYI, Y. S. AND REISCH, B. I. 1984b. Attempted egg transformation in Zea mays L. using irradiated pollen. Theoretical and Applied Genetics, 68, 269-275.

SNAPE, J. W., PARKER, B. B., SIMPSON, E., AINSWORTH, C. C., PAYNE, P. I. AND LAW, C. N. 1983. The use of irradiated pollen for differential gene transfer in wheat (Triticum aestivum). Theoretical and Applied Genetics, 65, 103-111.

SNEDECOR, G. W. ANI COC.HRAN, V. E. 1980. Statistical Methods. 7th edition. Iowa State University Press.

WERNER, C. P. 1984. The consequences of pollen irradiation in Nicotiana rustica. Ph.D. Thesis, University of Birmingham.

WERNER, C. P. AND CORNISH, M. A. 1984. Gene transfer in Nicotiana rustica by means of irradiated pollen. III. Cytogenetical consequences in the second generation. Heredity, 53, 545-551.

WERNER, C. P. AND CORNISH, M. A. 1985. Gene transfer in Nicotiana rustica by means of irradiated pollen. IV. Qualitative characters. Heredity, 55, 315-320.

WERNER, C. P., DUNKIN, I. M., CORNISH, M. A. AND JONES, G. H. 1984. Gene transfer in Nicotiana rustica by means of irradiated pollen. II. Cytogenetical consequences. Heredity, 52, 113-119. 